\title{
Identifying Factors Contributing to the Motorcycle Crash Severity in Pakistan
}

\author{
Amjad Pervez $\left(\mathbb{D}\right.$, Jaeyoung Lee $\mathbb{D}^{D}$, and Helai Huang $(\mathbb{D}$ \\ School of Traffic and Transportation Engineering, Central South University, Changsha 410075, China \\ Correspondence should be addressed to Jaeyoung Lee; jaeyoung@knights.ucf.edu
}

Received 21 November 2020; Revised 30 December 2020; Accepted 10 February 2021; Published 28 February 2021

Academic Editor: Eleonora Papadimitriou

Copyright (c) 2021 Amjad Pervez et al. This is an open access article distributed under the Creative Commons Attribution License, which permits unrestricted use, distribution, and reproduction in any medium, provided the original work is properly cited.

\begin{abstract}
Motorcycle is a popular mode of transportation in many developing countries, including Pakistan. Since the last decade, the registered number of motorcycles in Pakistan has increased by six times, constituting $74 \%$ of the total registered vehicles. However, limited research efforts have been made to investigate motorcycle-related safety issues in Pakistan. Thus, the relationship between potential risk factors and injury outcomes of motorcycle crashes is still unclear in the country. This study, therefore, established a random parameter logit model to examine the factors associated with the motorcycle injury severity. The analysis is based on two years (2014-2015) of data collected through the road traffic injuries surveillance system from Karachi city, Pakistan. The results indicate that the summer season, weekends, nighttime, elderly riders, heavy vehicle, and single-vehicle collisions are positively associated with fatalities, while the presence of pillion passengers and motorcycle-to-motorcycle crashes are negatively associated with fatalities. More importantly, in the specific context of Pakistan, morning hours, young riders, and female pillion passengers whose clothes stuck in the wheel significantly increase the fatal injury outcomes. Based on the findings, potential countermeasures to improve motorcycle safety are discussed, such as strict enforcement to control motorcyclists' risky behavior and speeding, provision of exclusive motorcycles lanes, and education of female pillion passengers. The findings from this study would increase awareness of motorcycle safety and can be used by the policymakers to enhance road safety in Pakistan, as well as in other developing countries with similar situations.
\end{abstract}

\section{Introduction}

Road traffic crashes account for more than 1.35 million fatalities each year, and almost half of these fatalities are among the vulnerable road users: motorcyclists (28\%), pedestrians (23\%), and bicyclists (3\%) [1]. Among the vulnerable road users, motorcyclists are inherently susceptible to more injuries than car occupants due to the lack of protection [2-4]. For instance, motorcyclist's fatality rate is 28 times higher than that of car occupants [5].

In many developing countries, including Pakistan, motorcycle crashes are a major safety challenge due to the rapid motorization [6]. Over the last decade, Pakistan has witnessed a substantial increase $(268 \%)$ in the registered motorized vehicles, especially in the motorcycles (613\%). According to a 2018 statistics, motorcycles constitute nearly $74 \%$ of the total registered vehicles in Pakistan [7].
Nevertheless, the general road and traffic safety conditions in Pakistan, like other developing countries, are not satisfactory. Thus, the rapid increase in motorcycles combined with inadequate road safety conditions has led to increased motorcycle crashes. For example, in the biggest city (Karachi) of Pakistan, motorcyclists are involved in almost $45 \%$ of the total road crashes [8].

Despite the pressing safety issues brought by motorcycles, the existing literature in Pakistan regarding motorcycle safety is limited. Most of the studies [9-13] have focused on the helmet use and laws, while only Waseem et al. [14] carried out the injury severity analysis. Thus, more countryspecific studies are required to understand the effect of various factors (traffic, road, environment, and rider) on the occurrence of motorcycle crashes. Apart from that, in Pakistan, guidelines are available to implement a partial motorcycle safety system. However, these guidelines are 
evolved in the developed countries where the main components (roads, vehicles, and drivers) of the transportation system are entirely different from those in Pakistan. For instance, mixed traffic comprising fast- and slow-moving vehicles, congested lanes, and non-compliance with traffic rules and safety are common in Pakistan. Specifically, motorcycle-related safety problems such as speeding, underage riding, red-light running, riding without helmets, and lenient policy enforcement are some of the examples $[9-11,15]$. Another fact is that, in the US, Canada, and Europe, motorcycle is used for leisure and touring purposes [3], while in Pakistan, due to lower purchasing costs, convenient parking, and absence of adequate public transportation, motorcycles become an essential means to perform various social and economic activities for many low- and middle-income families. Therefore, it is expected that the motorcyclists' injury severities risk factors in Pakistan may likely to vary from those in the developed countries.

The present study attempted to narrow the existing research gap about the motorcyclists' injury severity analysis in Pakistan. Based on the data collected from the most populous city in Pakistan-Karachi, a random parameter model is employed to estimate the significant factors for injury severity of motorcycle crashes. Furthermore, various safety specific countermeasures are suggested based on the research findings to improve motorcycle safety in Pakistan.

\section{Literature Review}

Research efforts have been made to explore the various key factors associated with the injury severity of motorcycle crashes. Among the motorcyclists' specific characteristics, the riders' age is an important factor that affects the severity of motorcycle crashes. Young and inexperienced riders tend to take risky behaviors that increase the risk of being involved in a crash [16-18], while older motorcyclists are involved in fatal crashes due to their slower reaction and perception time and decreased physical resiliency [19-22]. Apart from the age of the rider, driving experience also significantly affects the motorcycle crash outcomes. Lin and Kraus [23] summarized that novice riders are associated with a higher risk of motorcycle crashes and injuries.

Various behaviors, such as non-helmet use, and speeding, can significantly increase the severity outcome of a crash. For example, studies [21, 24, 25] concluded that nonhelmet riders suffer more head injuries, which result in fatal crash outcomes compared to the helmeted riders. Vlahogianni et al. [26] and Lin and Kraus [23] also summarized that enforcement of helmet use laws can significantly improve the motorcycle safety. Similarly, studies [21, 23, 25, 27] have shown that speeding substantially contributes to higher fatal crash outcomes. This could be attributed to the difficulty associated with higher speeds in braking and performing other safety maneuvers in hazardous situations.

Motorcycle collisions with heavier vehicles increase the risk of severe injury outcomes $[17,20,28]$. This could be due to the larger momentum of heavy vehicles and less attentiveness of their drivers towards motorcyclists. Motorcycles with heavy engines have greater performance that gives less reaction time to the riders in the event of a collision, thus, increasing the likelihood of fatal or injury outcomes [20, 29]. Past studies $[17,20,21]$ have shown that motorcycle collisions with fixed objects result in more fatal injuries.

In addition to the above, geometric characteristics, road surface, lighting, and visibility conditions actively contribute to the motorcycle crashes. Regarding the geometric characteristics, Schneider and Savolainen [30] have found that horizontal curves, shoulders width, and longitudinal slopes are responsible for increased motorcycle injury severity. Studies $[18,21]$ suggested that pavement friction, patches, loose materials, potholes, poor road markings, and wet road surfaces have been associated with severe injury outcomes. Savolainen and Mannering [21] concluded that poor visibility due to curves, slopes, or insufficient lighting results in more severe injuries. Moreover, without sufficient street lighting, riding at nighttime significantly increases the risk of severe injury outcomes $[19,28]$.

\section{Data Description}

The present study is based on the dataset collected from Karachi, the largest city of Pakistan [7], where motorcycles account for two-thirds of the total registered vehicles [8]. The motorcycle crash data were obtained from the road traffic injury surveillance system under the road traffic injury research project established in five highvolume emergency departments, namely, Abbasi Shaheed Hospital, Aga Khan University Hospital, Civil Hospital Karachi, Jinnah Post-Graduate Medical Centre, and Liaquat National Hospital from January $1^{\text {st }}, 2014$, to December $31^{\text {st }}, 2015$. The locations of the medical centers are shown in Figure 1. Previous studies [8, 31] have shown that the selected centers receive half to threefourths of the total road crashes in the city.

The final dataset consists of a total of 28,894 motorcycle crashes. In this study, based on the information obtained from the surveillance system, crash severity is divided into two categories: fatal and non-fatal crashes. Of the selected crashes, only $1.5 \%$ were fatal, while the remaining were non-fatal crashes. The dataset contains various information of a traffic crash such as the demographic characteristics of the casualties, type of vehicles involved in crashes, cause of the crash, collision types, time and location of the crash. Table 1 shows the descriptive statistics of the variables.

The descriptive analysis of the data showed that most of the victims were motorcycle riders (90.24\%). Male victims account for $85.37 \%$ of the total crashes, since in Pakistan, generally, males ride motorcycles as riders while females as pillion passengers due to the social and cultural constraints. The frequency of motorcycle crashes was relatively higher during weekdays (70.20\%) and in the summer season (27.11\%). During off-peak hours, the proportion of crashes was $68.70 \%$. Pedestrian collisions constitute a significant proportion of crashes (56.12\%) followed by motorcycle collisions $(31.30 \%)$. The frequency of crashes involving young riders $(48.55 \%)$ was the highest compared to other age groups. 


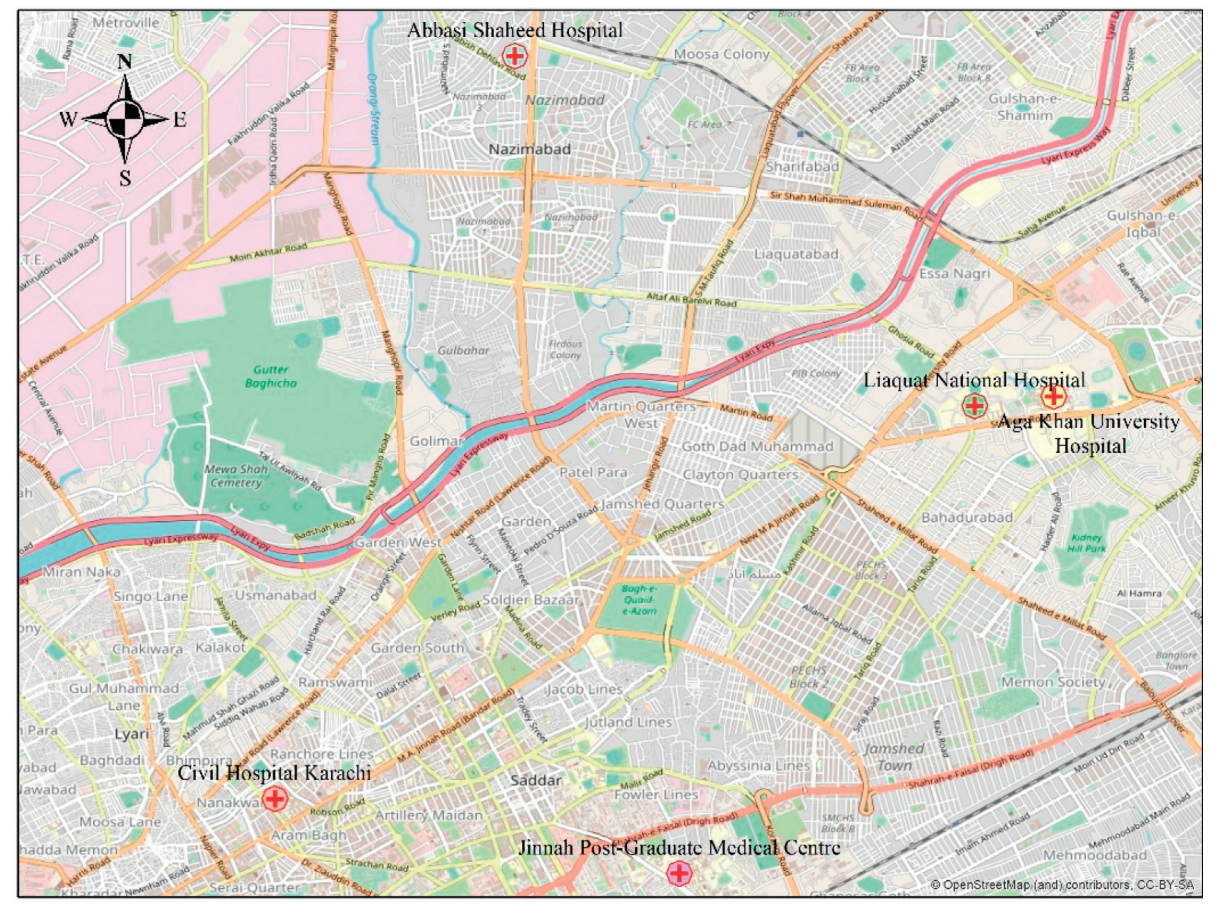

FIgURE 1: Location information of the medical centers.

\section{Methodological Background}

Various methods have been employed for the motorcyclists' injury severity analysis in the past. For instance, Lin et al. [17] used the proportional odds model to evaluate the injury severity of motorcycle crashes. Pai and Saleh [28] applied an ordered probit model to identify different factors that can affect the severity of crash injuries of motorcyclists. Haque et al. [18] developed a binary logit model to examine the factors affecting motorcycle crashes. Geedipally et al. [32] utilized a multinomial logit model to estimate the factors contributing to the motorcycle injury severity. Shaheed and Gkritza [25] estimated a latent class model to evaluate the risk factors associated with the injury severity of singlevehicle motorcycle crashes.

However, the traditional discrete choice models (binary, ordered logit, and probit models) have several limitations. First, these models consider the effect of the coefficients to be fixed across all crash observations. Second, some factors that influence crash severity are nearly impossible to be observed or collected. If these factors (unobserved heterogeneity) are considered with the observed ones, it may lead to biased inferences [33]. This issue can be addressed by estimating the random-parameter models, which allow the parameters' effect to vary across all crash observations. Therefore, several studies have recently employed the random parameter models to investigate motorcycle crash injury severities [24, 34-37].

In the present study, the available crash data include a large number of explanatory variables. These variables can be used directly, transformed, or interacted with other explanatory variables in the model estimation. However, we noted the unavailability of certain important factors in the data, such as the rider characteristics (e.g., helmet and clothes color), motorcycle-related factors (e.g., motorcycle mechanical condition, color, and type), traffic conditions (e.g., speed of the colliding vehicles and traffic volume), and riders' risk perception (e.g., aggressive, and risk-taking behavior). This may induce unobserved heterogeneity when establishing injury severity models. Therefore, to solve this problem, the present study will develop a random parameter model to analyze factors contributing to the injury severity of motorcycle crashes in Pakistan.

The dependent variable (i.e., injury severity) in this study is dichotomous with the response of interest as fatal crashes and non-fatal crashes. Therefore, binary logit models (fixed and random parameter) were estimated to explore the injury severity of motorcycle crashes in Pakistan. The models are formulated as follows.

The logit link function is as follows:

$$
\begin{aligned}
Y_{i} & \sim \operatorname{binomial}\left(p_{i}, n\right) \\
\log \text { it }\left(p_{i}\right) & =\log \left(\frac{p_{i}}{1-p_{i}}\right)=\beta_{o}+\sum_{k=1}^{K} \beta_{k} X_{i k}
\end{aligned}
$$

where $p_{i}$ denotes the probability of $Y_{i}=1$ (fatal outcome) and $1-p_{i}$ is the probability of $Y_{i}=0$ (non-fatal outcome), $X_{i k}$ is the $k$ th independent variable $(k=1,2, \ldots, K), \beta_{o}$ is the model constant, and $\beta_{k}$ are the parameter estimates for $k$ th independent variable.

The above-mentioned basic model assumes that each variable has a fixed effect across the crash observations. The effects of possible unobserved heterogeneity on the crash severity are ignored. Hence, the random parameter models are introduced that allow the explanatory variables to vary 
TABLE 1: Descriptive statistics of variables.

\begin{tabular}{|c|c|c|c|}
\hline Variable & Description & Frequency & Percentage \\
\hline \multirow{2}{*}{ Injury severity } & Non-fatal & 28460 & 98.50 \\
\hline & Fatal & 434 & 1.50 \\
\hline \multirow{4}{*}{ Season } & Spring & 6681 & 23.12 \\
\hline & Summer & 7833 & 27.11 \\
\hline & Autumn & 6734 & 23.31 \\
\hline & Winter & 7646 & 26.46 \\
\hline \multirow{2}{*}{ Day of week } & Weekends & 8610 & 29.80 \\
\hline & Weekdays & 20284 & 70.20 \\
\hline \multirow{6}{*}{ Time of day } & Morning $(06: 00-08: 59)$ & 1473 & 5.10 \\
\hline & Noon $(09: 00-11: 59)$ & 4550 & 15.75 \\
\hline & Afternoon (11:59-14:59) & 5469 & 18.93 \\
\hline & Early evening $(15: 00-17: 59)$ & 6042 & 20.90 \\
\hline & Late evening $(18: 00-20: 59)$ & 5955 & 20.61 \\
\hline & Night $(20: 59-05: 59)$ & 5405 & 18.71 \\
\hline \multirow{2}{*}{ Peak/Off-peak } & Peak & 9044 & 31.30 \\
\hline & Off-peak & 19850 & 68.70 \\
\hline \multirow[b]{2}{*}{ Collision type } & Single vehicle & 16152 & 55.90 \\
\hline & Multivehicle & 12742 & 44.10 \\
\hline \multirow{6}{*}{ Collision vehicle } & Bicycle & 56 & 0.44 \\
\hline & Motorcycle & 3988 & 31.30 \\
\hline & Passenger vehicle & 956 & 7.50 \\
\hline & Heavy vehicle & 242 & 1.90 \\
\hline & Pedestrian & 7151 & 56.12 \\
\hline & Other & 349 & 2.74 \\
\hline \multirow{2}{*}{ Pillion passenger } & Present & 2820 & 9.76 \\
\hline & Not present & 26074 & 90.24 \\
\hline \multirow{2}{*}{ Female pillion passenger cloth stuck in wheel } & Yes & 813 & 2.81 \\
\hline & No & 28081 & 97.19 \\
\hline \multirow{2}{*}{ Gender } & Male & 24668 & 85.37 \\
\hline & Female & 4226 & 14.63 \\
\hline \multirow{4}{*}{ Age } & $\leq 24$ & 14027 & 48.55 \\
\hline & $25-40$ & 9914 & 34.31 \\
\hline & $41-54$ & 3262 & 11.29 \\
\hline & $\geq 55$ & 1691 & 5.85 \\
\hline
\end{tabular}

individually $[33,38,39]$. The formulation of the random parameter $\beta_{i k}$ is as follows:

$$
\beta_{i k}=\beta_{k}+\varphi_{i k}
$$

where $\varphi_{i k}$ is a randomly distributed term, for instance, a normally distributed term with a mean of zero and variance of $\sigma_{k}^{2}$. The proposed random parameter logit model is estimated in the NLOGIT5 software on the basis of the maximum likelihood approach via 200 Halton draws [40]. Moreover, a significance level of $10 \%$ was used to assess whether a parameter is considered random or fixed.

\section{Results}

In order to avoid the existence of highly correlated variables, first, using the variance inflation factor (VIF), a correlation test was performed. The results indicated that the VIF has a maximum value of 2.54 for the age groups, 24-40 and 41-54, implying no strong multicollinearity exists among the independent variables in the data. To ensure that every added variable substantially enhances the model's overall efficiency, the log-likelihood ratio test was used. Different random parameter density functions, such as lognormal, normal, uniform, and triangular distributions, were evaluated. It was found that, compared to the other density functions, the normal distribution is statistically superior. Thus, it was selected to fit the random parameter model. Also, for comparison with the random parameter model, a fixed parameter binary logit model was developed.

Table 2 shows the overall goodness-of-fit for the estimated models. Results indicated that the random parameter model outperforms the fixed parameter model. Regarding the Akaike information criterion (AIC), the random parameter model (4302.107) has a lower value than the fixed parameter model (4317.223). Noticeably, while the performance of the random parameter model was comparable in terms of the AIC to that of the fixed parameter model, the likelihood ratio test revealed that the random parameter model at 95\% confidence level was statistically superior, with a $p$ value of 0.001 . Also, the presence of the four random variables showed that the random parameter model had 
TABle 2: Goodness-of-fit measures for fixed and random parameter models.

\begin{tabular}{lcc}
\hline Model & Fixed parameter model & Random parameter model \\
\hline Observations & 28894 & 28894 \\
Number of parameters & 12 & 16 \\
Log likelihood at zero & -2256.988 & -2256.988 \\
Log likelihood at convergence & -2145.611 & -2134.053 \\
AIC & 4317.223 & 4302.107 \\
\hline$\chi^{2}=-2$ [LL (fixed)-LL (random)] & & 11.558 \\
Degree of freedom & & 4 \\
$p$ value & & 0.021 \\
\hline
\end{tabular}

${ }^{*}$ Akaike information criterion, $\mathrm{AIC}=-2 \ln (L)+2 K$.

captured the heterogeneous effects of the risk factors, which result in better parameter estimates. Therefore, the following section presents the parameter estimation results obtained from the random parameter model.

Table 3 shows the estimation results of the random parameter model and the corresponding odds ratios. Specifically, crashes in summer (odds ratio $=1.220$ ), on weekends (1.155), during morning hours (4.594), nighttime (1.220), riders aged less than or equal to twenty-four years (1.329), and aged fifty-five years or older (2.670), female pillion passenger whose clothes stuck in the wheel (1.679), collisions with heavy vehicle (2.391), and single-vehicle crashes (1.488) all indicated a higher risk of crash severity. In contrast, crashes involving pillion passenger (0.115), and collisions with motorcycles (0.313) are associated with a lower risk of fatal crashes. In addition, the effects of factors including morning hours, collision with a motorcycle, crashes involving pillion passenger, and drivers aged fiftyfive years or above on crash severity tended to vary across all crash observations. The distributions of the random parameters are shown in Figure 2.

\section{Discussion}

6.1. Temporal Characteristics. Regarding the day of the week, crashes occurring on weekends are more fatal than those on weekdays. The high probability of fatal crashes on weekends in Pakistan is not surprising as on weekends, due to holidays, the young motorcyclists usually hang out. Consequently, they are involved in different risky behaviors, including speeding, drifting, one-wheeling competitions, and rash driving on the already congested roads. Descriptive statistics of the data also showed that young riders constitute almost $50 \%$ of the total fatal crashes on weekends. Similar results were concluded by studies from other developing countries [41-43].

Crashes occurring during the summer increase the probability of fatal injury outcomes. It is because the study area (Karachi city) has a subtropical climate with bright sunshine in the summer season, which results in significant visual impairment. In addition, the summer season is associated with lower helmet use due to the thermal discomfort, which in turn increases the risk of fatal crashes $[44,45]$. Moreover, the monsoon season in Karachi city is at its peak during the summer season; thus, the poor road surface conditions such as potholes, uneven surfaces, and
TABLE 3: Estimation results for the random parameter model.

\begin{tabular}{lcccc}
\hline Variable & Coefficient & $\begin{array}{c}\text { Odds } \\
\text { ratio }\end{array}$ & Std. err & $p$ \\
\hline Constant & $-3.826^{* * *}$ & - & 1.4162 & 0 \\
\hline $\begin{array}{l}\text { Environmental characteristics } \\
\text { Season (relative to autumn) }\end{array}$ & & & \\
$\begin{array}{l}\text { Summer } \\
\text { Day of week (relative to weekday) }\end{array}$ & 1.220 & 0.079 & 0.011 \\
$\begin{array}{l}\text { Weekends } \\
0.144^{* * *}\end{array}$ & 1.155 & 0.077 & 0.063 \\
$\begin{array}{l}\text { Time of day (relative to noon) } \\
\text { Morning }\end{array}$ & $1.525^{* * *}$ & 4.594 & 0.694 & $<0.01$ \\
Std. dev. morning & $2.884^{* * *}$ & - & 0.884 & $<0.01$ \\
Night & $0.199^{* *}$ & 1.220 & 0.088 & 0.022 \\
\hline
\end{tabular}

Motorcyclists' characteristics

Age (relative to 25-40)

$\begin{array}{lllll}\leq 24 & 0.284^{* * *} & 1.329 & 0.101 & 0.005\end{array}$

$\begin{array}{lllll}\geq 55 & 0.982^{* * *} & 2.670 & 0.125 & <0.01\end{array}$

Std. dev. $\geq 55 \quad 2.202^{* * *} \quad-\quad 0.1350 .025$

Pillion passenger (relative to no pillion passenger)

$\begin{array}{lllll}\text { Pillion passenger } & -2.157^{* * *} & 0.115 & 0.474 & <0.01\end{array}$

Std. dev. pillion passenger $\quad 2.730^{* * *} \quad-\quad 0.302<0.01$

Female pillion passenger cloth stuck in wheel (relative to no)

$\begin{array}{lllll}\text { Cloth stuck in wheel } & 0.518^{*} & 1.679 & 0.301 & 0.085\end{array}$

\begin{tabular}{lllll} 
(yes) & $0.518^{*}$ & 1.679 & 0.301 & 0.085 \\
\hline
\end{tabular}

Crash characteristics

Collision vehicle (relative to other)

$\begin{array}{lllll}\text { Motorcycle } & -1.161^{* * *} & 0.313 & 0.220<0.01\end{array}$

Std. dev. motorcycle $\quad 2.434^{* * *} \quad-\quad 0.178<0.01$

$\begin{array}{lllll}\text { Heavy vehicle } & 0.872^{* * *} & 2.391 & 0.189<0.01\end{array}$

Single vehicle $\quad 0.397^{* * *} \quad 1.488 \quad 0.107<0.01$

Symbols ${ }^{* * *},{ }^{* *}$, and ${ }^{*}$ indicate significance at $1 \%, 5 \%$, and $10 \%$ level, respectively. Random parameters are highlighted using italics.

poor drainage substantially increase the likelihood of fatal crashes.

The study found that crashes occurring during morning hours $(06: 00-08: 59)$ result in fatal injury outcomes. This could be due to the fact that, in the early morning hours, motorcyclists leaving for work or schools are involved in speeding and other risky riding behaviors. The morning variable is normally distributed with a mean of 1.525 and a standard deviation of 2.884 , and it increases the probability of fatal crashes by $70.15 \%$. Motorcyclists were more likely to sustain fatal injuries in crashes occurring during nighttime $(20: 59-05: 59)$. The reasons for the significantly high number of fatal crashes during nighttime are poor visibility 
0.20

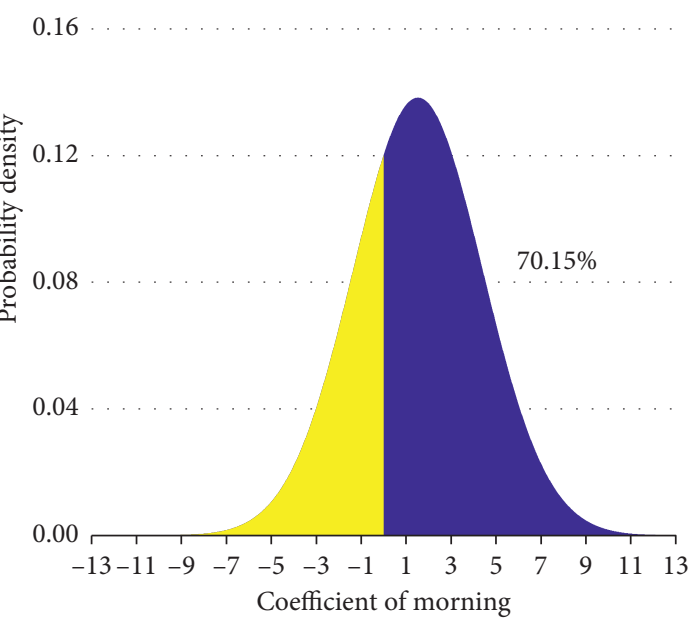

(a)

0.20

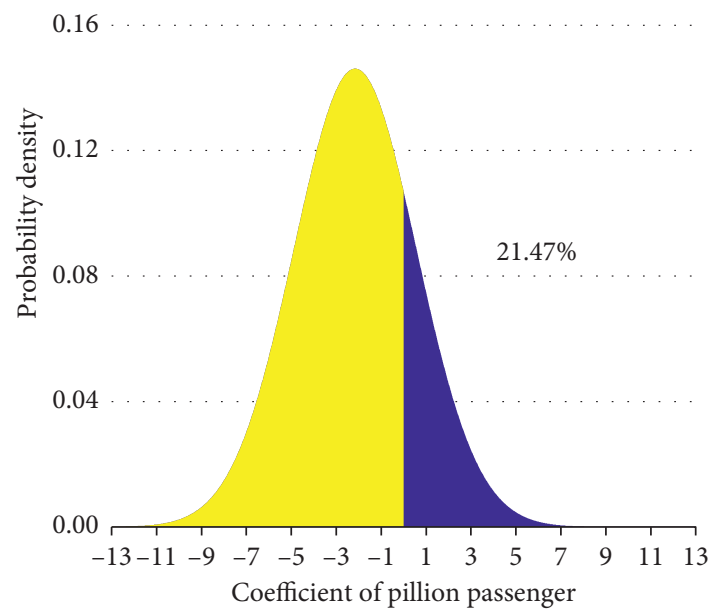

(c)

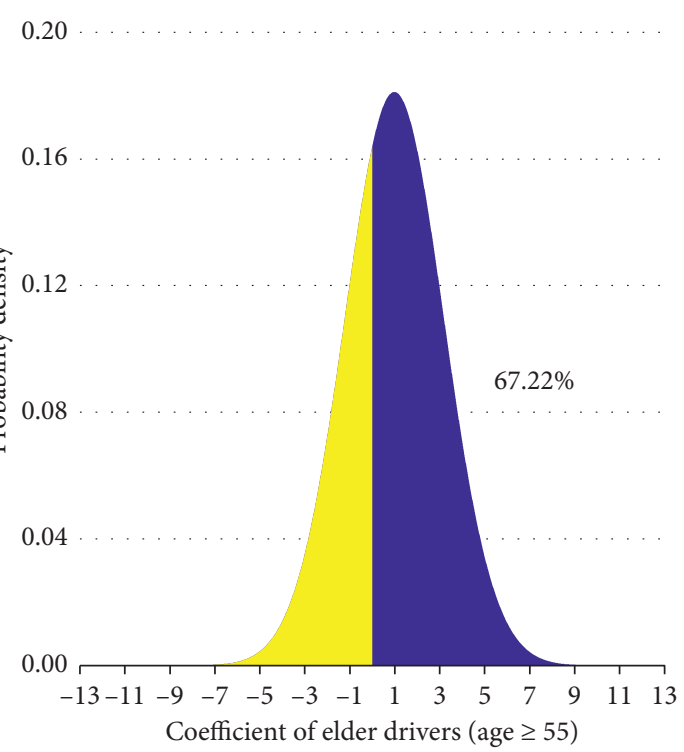

(b)

0.20

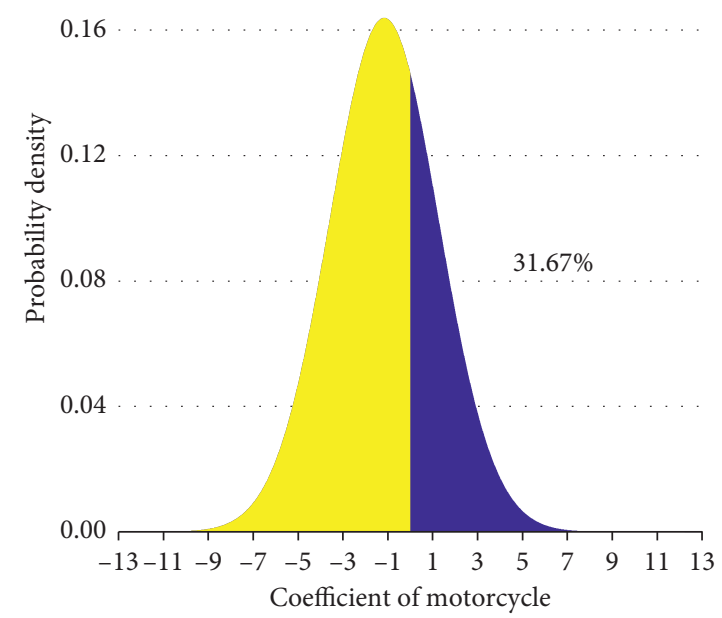

(d)

Figure 2: Plots of the estimated normal distributions of the random parameters.

conditions and riders' physical and psychological fatigue due to day-long activities. Studies [4, 28, 46, 47] also concluded that nighttime crashes are severe due to the increased speeds and riding without streetlamps.

6.2. Motorcyclists' Characteristics. The results indicated that crashes involving young (age $\leq 24)$ riders are more likely to be fatal. The high probability of fatal crashes in younger riders in Pakistan could be attributed to their lack of experience and risky behaviors such as one-wheeling, drifting, speeding, and ignoring traffic and safety regulations. Previous studies related to motorcycle safety in other developing countries also concluded similar findings $[48,49]$. The present study results also showed that, compared to middleaged $(25-40)$ riders, elderly riders (age $\geq 55)$ have a higher probability of getting fatally injured if involved in a motorcycle crash. This finding is expected since elderly riders have deteriorating health conditions and lower perceptionreaction time in hazardous situations $[21,24,32]$. The elderly age variable has a normally distributed coefficient ( mean $=0.982$ and standard deviation $=2.202$ ), suggesting that, in the $67.22 \%$ crash observations, the elderly riders increase the probability of fatal crashes (see Figure 2). The result is consistent with expectations as riders within the same age groups may result in different injury outcomes due to the difference in their driving habits, physical abilities, and other unobserved factors [50]. 
The presence of pillion passengers decreases the likelihood of sustaining fatal injuries. One possible reason is that riders are more careful with pillion passengers as the mass of the motorcycle increases. Also, the motorcycle is the primary mode of transportation in Pakistan, and generally, the pillion passenger is family or friend; thus, in their presence, the motorcyclists tend to drive more cautiously. Several previous studies [14, 51, 52] also concluded that a pillion passenger's presence lowers the likelihood of fatal crashes. The pillion passenger variable results in a random parameter with a normal distribution (mean $=-2.157$ and standard deviation $=2.730$ ), indicating that $78.53 \%$ of motorcycle crashes involving pillion passengers were less likely to result in fatal crashes.

The study found that crashes involving female pillion passengers whose clothes stuck in the wheel increase the likelihood of fatal injury outcomes. The higher probability of such fatal crashes is because females in Pakistan usually wear loose clothes in the form of kameez (long shirt) over shalwar (trouser) and long flowing burqa/abaya (overcoat). These garments have a higher chance of getting stuck in the rear wheel or chain of the motorcycles as, in Pakistan, the female pillion passengers sit on the motorcycle in a side-saddle manner [53], thus resulting in more fatal injuries [54]. Previous studies $[10,13]$ that examined the cloth-related injuries of pillion passengers in Karachi city also concluded similar results.

6.3. Crash Characteristics. Regarding the vehicle type, the study found that the motorcycle-motorcycle collision is associated with a lower probability of fatal crashes. This is primarily because the riders can easily see the approaching motorcycle, and they also have a lower momentum [21, 41]. The indicator variable is also normally distributed (mean $=-1.161$ and standard deviation $=2.434$ ). Given these distributional parameters, $68.33 \%$ of the distribution was less than zero, and $31.67 \%$ of the distribution was greater than zero. Thus, almost $68.33 \%$ of the collisions involving motorcycles were less likely to lead to fatal crashes.

The probability of a fatal injury outcome is higher in a multi-vehicle motorcycle crash involving heavy vehicles. This is due to the fact that motorcycles share the same lane with heavy vehicles as roads in Pakistan lack exclusive motorcycle lanes [14]. Thus, even a minor collision between the motorcycle and heavy vehicles can easily cause severe or fatal injury to the motorcyclists. Previous studies $[42,55]$ also concluded similar findings. The study also found that single-vehicle collisions significantly increase the risk of fatal crash outcomes. This might be attributed to the riders' lower tendency to wear helmets and speeding (common motorcycle safety-related issues in Pakistan). Waseem et al. [14], Jou et al. [51], and Naqvi et al. [56] also concluded similar findings from other developing countries.

6.4. Policy Implications. Young motorcyclists are generally exposed to greater risk in traffic crashes than elder motorcyclists. It is mainly because young riders are usually inexperienced and tend to be involved in traffic and safety violations, which increases the risk of injuries [57]. In Pakistan, the phenomenon of rash driving and disobedience of safety regulations among young motorcyclists is a significant and common problem. Moreover, teenagers ride motorcycles without a license, as the license in Pakistan can only be obtained at age 18 or above. Therefore, formal rider training, aiming to minimize the risk of motorcycle injuries by enhancing the riding skills, should be made compulsory in the motorcycle license program. Parental management of teenage driving should also be promoted as it significantly reduces motorcycle fatalities among teenage and young riders [58].

The study found that collisions involving heavy vehicles increase the probability of fatal injuries. It can be minimized through segregating the motorcyclists from the mixed traffic by providing specific lanes for motorcycles. In this regard, experience from another developing country (Malaysia) can be taken, where the provision of exclusive motorcycle lanes resulted in a $600 \%$ reduction of motorcycle-related fatalities [59].

Clothes-related crashes of a female pillion passenger, who wears traditional loose clothes and scarfs, is an influential factor that contributes to fatal crashes in the South Asian countries, including Pakistan [12, 54]. In this regard, the present study recommends that, first, public awareness regarding injuries caused by the loose garments should be spread. Second, females should be educated to properly wrap their loose clothes/scarfs while riding the motorcycles. Third, the local motorcycle manufacturers should be asked to design specific covers for the motorcycles' rear wheel and chains to minimize clothes to be stuck in the motorcycle.

Finally, other efficient preventive measures such as an increase in helmet use, provision of streetlights to improve the visibility on roads, periodic road maintenance, and enforcement of speed violations can be directly adopted by Pakistan. Apart from these interventions, legislation, education, and public awareness campaigns are significant ways to reduce road traffic injuries over time [60].

\section{Conclusions}

In Pakistan, the growing number of motorcycles raises safety concerns. However, the corresponding research efforts to improve motorcycle safety are scarce. Therefore, this paper attempted to investigate the motorcyclists' injury severities using the crash data obtained from the road traffic injuries surveillance system, set up in Karachi, Pakistan. A random parameter model is estimated based on 28,894 motorcycle crashes collected from January $1^{\text {st }}, 2014$, to December $31^{\text {st }}$, 2015. Two crash injury outcomes, i.e., fatal and non-fatal, were considered in this paper. The risk factors consisting of temporal characteristics, motorcyclists' characteristics, and crash specific characteristics were evaluated for motorcycleinjury severity. The results showed that, compared to the autumn season, the summer season results in more fatal crashes. Crashes occurring on weekends are more fatal than those on weekdays. Early morning hours and nighttime are associated with increased fatal injury outcomes. Crashes 
involving young and elderly riders have a higher likelihood of fatality. Motorcycle crashes that occurred due to female pillion passenger clothes stuck in wheel result in fatal injuries. Heavy vehicle and single-vehicle collisions are positively associated with fatal injury outcomes. Finally, the possibility of fatal injuries decreases for motorcycle-motorcycle crashes and the ones that involve pillion passengers.

It is necessary and desirable to import the effective existing countermeasures from the developed countries to reduce the motorcycle injury severities in Pakistan. However, the transportation system, traffic policies, motorcycle purpose, and usage in Pakistan are significantly different from those of developed countries. It is possible that if these differences are not taken into account, the interventions may not be effective. Therefore, it is necessary to understand the cost, feasibility, and other potential challenges in the implementation and successful transfer of the interventions. Based on the findings, possible countermeasures to improve motorcycle safety are discussed, such as strict enforcement to control risky behavior and speeding of motorcyclists, provision of exclusive motorcycles lanes, and education of female pillion passengers.

Although some of the present study results are in line with existing studies that have explored the motorcycle injury severity, however, the present study has increased importance as the findings are likely to generate more debates and concerns in the country regarding motorcycle safety and can be used by the policymakers to enhance road safety in Pakistan. Finally, it should be noted that the present study was based on two years of data collected from a surveillance system, which has inadequacies such as unavailability of some relevant variables and underreporting of injury crashes. Therefore, in the future, more empirical studies should be conducted using comprehensive data to understand the motorcyclists' injury severities in Pakistan.

\section{Data Availability}

Some or all data that support the findings of this study are available from the corresponding author upon reasonable request.

\section{Conflicts of Interest}

The authors declare that there are no conflicts of interest regarding the publication of this paper.

\section{Acknowledgments}

The authors acknowledge the management of the road traffic injuries surveillance system for their assistance in data collection. This study was funded by the National Key R\&D Program of China (2020YFB1600400) and the InnovationDriven Project of Central South University (2020CX013).

\section{References}

[1] WHO, Global Status Report on Road Safety 2018: Supporting a Decade of Action, WHO, Luxembourg, Europe, 2018.
[2] D. Eustace, V. K. Indupuru, and P. Hovey, "Identification of risk factors associated with motorcycle-related fatalities in Ohio," Journal of Transportation Engineering, vol. 137, no. 7, pp. 474-480, 2011.

[3] N. Haworth, "Powered two wheelers in a changing worldChallenges and opportunities," Accident Analysis \& Prevention, vol. 44, no. 1, pp. 12-18, 2012.

[4] S. M. Rifaat, R. Tay, and A. De Barros, "Severity of motorcycle crashes in Calgary," Accident Analysis \& Prevention, vol. 49, pp. 44-49, 2012.

[5] WHO, National Highway Traffic Safety Administration Traffic Safety Facts 2013 Data: Motorcycle, WHO, Washington, DC, USA, 2015.

[6] M. O. Esmael, K. Sasaki, and K. Nishii, "Road traffic accident trend in developing countries- the policy implications," Journal of the Eastern Asia Society for Transportation Studies, vol. 10, pp. 1-13, 2013.

[7] Pakistan Bureau of Statistics, Pakistan Statistical Yearbook, Pakistan Bureau of Statistics, Islamabad, Pakistan, 2018.

[8] S. Shamim, J. A. Razzak, R. Jooma, and U. Khan, "Initial results of Pakistan's first road traffic injury surveillance project," International Journal of Injury Control and Safety Promotion, vol. 18, no. 3, pp. 213-217, 2011.

[9] J. A. Bhatti, K. Ejaz, J. A. Razzak, I. A. Tunio, and I. Sodhar, "Influence of an enforcement campaign on seat-belt and helmet wearing, Karachi-Hala Highway, Pakistan," Annals of Advances in Automotive Medicine. Association for the Advancement of Automotive Medicine. Annual Scientific Conference, vol. 55, pp. 65-70, 2011.

[10] I. Ahmed, T. Islam, G. Ali, and M. M. Nawaz, "Pillion riders' cloth related injuries and helmet wearing patterns: a study of Lahore, Pakistan," International Journal of Injury Control and Safety Promotion, vol. 23, no. 4, pp. 388-394, 2016.

[11] I. Khan, A. Khan, F. Aziz, M. Islam, and S. Shafqat, "Factors associated with helmet use among motorcycle users in Karachi, Pakistan," Academic Emergency Medicine, vol. 15, no. 4, pp. 384-387, 2008.

[12] U. R. Khan, J. A. Bhatti, M. S. Shamim, N. Zia, J. A. Razzak, and R. Jooma, "Clothing-related motorcycle injuries in Pakistan: findings from a surveillance study," International Journal of Injury Control and Safety Promotion, vol. 22, no. 4, pp. 308-313, 2015.

[13] M. S. Minhas, M. M. Sangani, K. Mehmood, A. Bhatti, A. Mughal, and R. Kumar, "Dupatta (long scarf) related injuries in female pillion riders in Karachi Pakistan," JPMA. The Journal of the Pakistan Medical Association, vol. 66, no. 11, pp. 1458-1461, 2016.

[14] M. Waseem, A. Ahmed, and T. U. Saeed, "Factors affecting motorcyclists' injury severities: an empirical assessment using random parameters logit model with heterogeneity in means and variances," Accident Analysis \& Prevention, vol. 123, pp. 12-19, 2019.

[15] U. Farooq, An Analysis of Legislation and Level of Compliance of Key Crash Risk Factors-a Case Study of Islamabad, National University of Sciences and Technology, Islamabad, Pakistan, 2017.

[16] T.-H. Yeh and H.-L. Chang, "Age and contributing factors to unlicensed teen motorcycling," Safety Science, vol. 47, no. 1, pp. 125-130, 2009.

[17] M.-R. Lin, S.-H. Chang, W. Huang, H.-F. Hwang, and L. Pai, "Factors associated with severity of motorcycle injuries among young adult riders," Annals of Emergency Medicine, vol. 41, no. 6, pp. 783-791, 2003. 
[18] M. M. Haque, H. C. Chin, and H. Huang, "Modeling fault among motorcyclists involved in crashes," Accident Analysis \& Prevention, vol. 41, no. 2, pp. 327-335, 2009.

[19] M. De Lapparent, "Empirical Bayesian analysis of accident severity for motorcyclists in large French urban areas," Accident Analysis \& Prevention, vol. 38, no. 2, pp. 260-268, 2006.

[20] M. A. Quddus, R. B. Noland, and H. C. Chin, "An analysis of motorcycle injury and vehicle damage severity using ordered probit models," Journal of Safety Research, vol. 33, no. 4, pp. 445-462, 2002.

[21] P. Savolainen and F. Mannering, "Probabilistic models of motorcyclists' injury severities in single-and multi-vehicle crashes," Accident Analysis \& Prevention, vol. 39, no. 5, pp. 955-963, 2007.

[22] S. Nunn, "Death by motorcycle: background, behavioral, and situational correlates of fatal motorcycle collisions," Journal of Forensic Sciences, vol. 56, no. 2, pp. 429-437, 2011.

[23] M.-R. Lin and J. F. Kraus, "A review of risk factors and patterns of motorcycle injuries," Accident Analysis \& Prevention, vol. 41, no. 4, pp. 710-722, 2009.

[24] F. Chang, M. Li, P. Xu, H. Zhou, M. Haque, and H. Huang, "Injury severity of motorcycle riders involved in traffic crashes in Hunan, China: a mixed ordered logit approach," International Journal of Environmental Research and Public Health, vol. 13, no. 7, p. 714, 2016.

[25] M. S. Shaheed and K. Gkritza, "A latent class analysis of single-vehicle motorcycle crash severity outcomes," Analytic Methods in Accident Research, vol. 2, pp. 30-38, 2014.

[26] E. I. Vlahogianni, G. Yannis, and J. C. Golias, "Overview of critical risk factors in Power-Two-Wheeler safety," Accident Analysis \& Prevention, vol. 49, pp. 12-22, 2012.

[27] A. Theofilatos and A. Ziakopoulos, "Examining injury severity of moped and motorcycle occupants with real-time traffic and weather data," Journal of Transportation Engineering, Part A: Systems, vol. 144, no. 11, Article ID 04018066, 2018.

[28] C.-W. Pai and W. Saleh, "An analysis of motorcyclist injury severity under various traffic control measures at three-legged junctions in the UK," Safety Science, vol. 45, no. 8, pp. 832-847, 2007.

[29] C.-W. Pai, "Motorcyclist injury severity in angle crashes at T-junctions: identifying significant factors and analysing what made motorists fail to yield to motorcycles," Safety Science, vol. 47, no. 8, pp. 1097-1106, 2009.

[30] W. H. Schneider and P. T. Savolainen, "Comparison of severity of motorcyclist injury by crash types," Transportation Research Record: Journal of the Transportation Research Board, vol. 2265, no. 1, pp. 70-80, 2011.

[31] M. U. Lateef, "Estimation of fatalities due to road traffic crashes in Karachi, Pakistan, using capture-recapture method. Asia," Pac. J. Public Health, vol. 22, pp. 332-341, 2010.

[32] S. R. Geedipally, P. A. Turner, and S. Patil, "Analysis of motorcycle crashes in Texas with multinomial logit model," Transportation Research Record: Journal of the Transportation Research Board, vol. 2265, no. 1, pp. 62-69, 2011.

[33] F. L. Mannering and C. R. Bhat, "Analytic methods in accident research: methodological frontier and future directions," Analytic Methods in Accident Research, vol. 1, pp. 1-22, 2014.

[34] M. S. B. Shaheed, K. Gkritza, W. Zhang, and Z. Hans, "A mixed logit analysis of two-vehicle crash severities involving a motorcycle," Accident Analysis \& Prevention, vol. 61, pp. 119-128, 2013.

[35] F. Chang, P. Xu, H. Zhou, A. H. S. Chan, and H. Huang, "Investigating injury severities of motorcycle riders: a twostep method integrating latent class cluster analysis and random parameters logit model," Accident Analysis \& Prevention, vol. 131, pp. 316-326, 2019.

[36] B. Wali, A. J. Khattak, and N. Ahmad, "Examining correlations between motorcyclist's conspicuity, apparel related factors and injury severity score: evidence from new motorcycle crash causation study," Accident Analysis \& Prevention, vol. 131, pp. 45-62, 2019.

[37] A. Farid and K. Ksaibati, "Modeling severities of motorcycle crashes using random parameters," Journal of Traffic and Transportation Engineering (English Edition), 2020, In press.

[38] F. Chen, M. Song, and X. Ma, "Investigation on the injury severity of drivers in rear-end collisions between cars using a random parameters bivariate ordered probit model," International Journal of Environmental Research and Public Health, vol. 16, no. 14, p. 2632, 2019.

[39] Z. Li, Q. Wu, Y. Ci, C. Chen, X. Chen, and G. Zhang, "Using latent class analysis and mixed logit model to explore risk factors on driver injury severity in single-vehicle crashes," Accident Analysis \& Prevention, vol. 129, pp. 230-240, 2019.

[40] W. H. Greene, NLOGIT 5: Reference Guide, Econometric Software, Inc., NewYork, NY, USA, 2012.

[41] L. Wahab and H. Jiang, "A multinomial logit analysis of factors associated with severity of motorcycle crashes in Ghana," Traffic Injury Prevention, vol. 20, no. 5, pp. 521-527, 2019.

[42] S. Jung, Q. Xiao, and Y. Yoon, "Evaluation of motorcycle safety strategies using the severity of injuries," Accident Analysis \& Prevention, vol. 59, pp. 357-364, 2013.

[43] E. N. Aidoo and R. Amoh-Gyimah, "Modelling the risk factors for injury severity in motorcycle users in Ghana," Journal of Public Health, vol. 28, no. 2, pp. 199-209, 2020.

[44] L.-P. Li, G.-L. Li, Q.-E. Cai, A. L. Zhang, and S. K. Lo, "Improper motorcycle helmet use in provincial areas of a developing country," Accident Analysis \& Prevention, vol. 40, no. 6, pp. 1937-1942, 2008.

[45] K. Gkritza, "Modeling motorcycle helmet use in Iowa: evidence from six roadside observational surveys," Accident Analysis \& Prevention, vol. 41, no. 3, pp. 479-484, 2009.

[46] M. M. Abdul Manan, A. Várhelyi, A. K. Çelik, and H. H. Hashim, "Road characteristics and environment factors associated with motorcycle fatal crashes in Malaysia," IATSS Research, vol. 42, no. 4, pp. 207-220, 2018.

[47] M. Abrari Vajari, K. Aghabayk, M. Sadeghian, and N. Shiwakoti, "A multinomial logit model of motorcycle crash severity at Australian intersections," Journal of Safety Research, vol. 73, pp. 17-24, 2020.

[48] R. Dandona, G. A. Kumar, and L. Dandona, "Risky behavior of drivers of motorized two wheeled vehicles in India," Journal of Safety Research, vol. 37, no. 2, pp. 149-158, 2006.

[49] A. Barzegar, M. Ghadipasha, M. Forouzesh, S. Valiyari, and A. Khademi, "Epidemiologic study of traffic crash mortality among motorcycle users in Iran (2011-2017)," Chinese Journal of Traumatology, vol. 23, no. 4, pp. 219-223, 2020.

[50] D. N. Moore, W. H. Schneider, P. T. Savolainen, and M. Farzaneh, "Mixed logit analysis of bicyclist injury severity resulting from motor vehicle crashes at intersection and nonintersection locations," Accident Analysis \& Prevention, vol. 43, no. 3, pp. 621-630, 2011.

[51] R.-C. Jou, T.-H. Yeh, and R.-S. Chen, "Risk factors in motorcyclist fatalities in Taiwan," Traffic Injury Prevention, vol. 13, no. 2, pp. 155-162, 2012.

[52] A. Moskal, J.-L. Martin, and B. Laumon, "Risk factors for injury accidents among moped and motorcycle riders," Accident Analysis \& Prevention, vol. 49, pp. 5-11, 2012. 
[53] U. Khan, N. Zia, S. Awan, and A. Khan, "SP5-27 Perception of Pakistani women pillion riders about helmet use: a qualitative study," Journal of Epidemiology \& Community Health, vol. 65, no. 1, p. A452, 2011.

[54] A. A. Siddiqui, M. S. Shamim, R. Jooma, and S. A. Enam, "Long scarf injuries," Journal of the College of Physicians and Surgeons Pakistan, vol. 16, pp. 152-153, 2006.

[55] J. Oxley, M. D. Ravi, J. Yuen, E. Hoareau, and H. H. Hashim, "Identifying contributing factors to fatal and serious injury motorcycle collisions involving children in Malaysia," in Proceedings of the Annals of Advances in Automotive Medicine, Barrington, IL, USA, September 2013.

[56] H. M. Naqvi and G. Tiwari, "Factors contributing to motorcycle fatal crashes on National Highways in India," International Journal of Injury Control and Safety Promotion, vol. 25 , no. 3, p. 319, 2018.

[57] R. Elvik, "Why some road safety problems are more difficult to solve than others," Accident Analysis \& Prevention, vol. 42, no. 4, pp. 1089-1096, 2010.

[58] J. L. Hartos, P. Eitel, D. L. Haynie, and B. G. Simons-Morton, "Can I take the car?" Journal of Adolescent Research, vol. 15, no. 3, pp. 352-367, 2000.

[59] R. S. Radin Umar, "Motorcycle safety programmes in Malaysia: how effective are they?" International Journal of Injury Control and Safety Promotion, vol. 13, no. 2, pp. 71-79, 2006.

[60] C. Staton, J. Vissoci, E. Gong et al., "Road traffic injury prevention initiatives: a systematic review and metasummary of effectiveness in low and middle income countries," PLoS One, vol. 11, no. 1, Article ID e0144971, 2016. 